\title{
Assessing Vehicle Emissions from a Multi-Lane to Turbo Roundabout Conversion Using a Microsimulation Tool
}

\author{
Maksymilian Mądziel ${ }^{1, *(\mathbb{D})}$, Tiziana Campisi ${ }^{2, *} \mathbb{D}$, Artur Jaworski ${ }^{1}$ (D) Hubert Kuszewski ${ }^{1}$ (D) and Paweł Woś ${ }^{1}$ \\ 1 Faculty of Mechanical Engineering and Aeronautics, Rzeszow University of Technology, \\ 35-959 Rzeszów, Poland; ajaworsk@prz.edu.pl (A.J.); hkuszews@prz.edu.pl (H.K.); pwos@prz.edu.pl (P.W.) \\ 2 Faculty of Engineering and Architecture, Kore University of Enna, Cittadella Universitaria, 94100 Enna, Italy \\ * Correspondence: mmadziel@prz.edu.pl (M.M.); tiziana.campisi@unikore.it (T.C.); \\ Tel.: +48-178651679 (M.M.); +39-3299433498 (T.C.)
}

Citation: Mądziel, M.; Campisi, T.; Jaworski, A.; Kuszewski, H.; Woś, P. Assessing Vehicle Emissions from a Multi-Lane to Turbo Roundabout Conversion Using a Microsimulation Tool. Energies 2021, 14, 4399. https:// doi.org/10.3390/en14154399

Academic Editors: Fabio Orecchini and Valery Vodovozov

Received: 19 May 2021

Accepted: 20 July 2021

Published: 21 July 2021

Publisher's Note: MDPI stays neutral with regard to jurisdictional claims in published maps and institutional affiliations.

Copyright: (c) 2021 by the authors. Licensee MDPI, Basel, Switzerland. This article is an open access article distributed under the terms and conditions of the Creative Commons Attribution (CC BY) license (https:// creativecommons.org/licenses/by/ $4.0 /)$.

\begin{abstract}
The development of urban strategies for the reduction of environmental impacts and decarbonization requires ongoing monitoring from the local scale and further deployment of actions to improve transport demand (user characteristics and modal choice) and supply (infrastructure and services). The analysis of pollution sources and the evaluation of possible scenarios are preliminary to the mitigation of impacts. In particular, the study of geometrical and functional characteristics of infrastructures through micro-simulation allows understanding of which schemes can support the reduction of emissions and guarantee high levels of service (LOS), reducing the problem of vehicular congestion in urban areas. The present work focuses on the small-scale analysis of vehicular traffic emissions at multi-lane roundabout road intersection and the comparison of geometric schemes (current and design) and use with a turbo roundabout scheme as traffic volumes changes. These volumes have plummeted due to the current COVID-19 pandemic. The results show that the geometric-functional modification of the roundabout intersection from a multi-lane to a turboroundabout intersection allows a reduction of up to $30 \%$ of the emissions considering the current composition of the traffic fleet in the city of Rzeszow in Poland. The proposed comparative analysis methodology can contribute to the drafting of sustainable urban mobility plans (SUMPs) proposing a set of investments for new road works and considering a number of scenarios with interventions that can be implemented in the medium and long term that can provide the incentive to reduce road congestion and vehicular emissions.
\end{abstract}

Keywords: vehicle emission; roundabouts; $\mathrm{CO}_{2}$ emission; vehicle movement modelling

\section{Introduction}

Air pollution in general is among the causes contributing to climate change, causing an environmental risk to human health [1]. The main cause of climate change is the greenhouse effect. Many of these gases occur naturally, but human activity increases the concentrations of some of them in the atmosphere, particularly carbon dioxide $\left(\mathrm{CO}_{2}\right)$ and nitrogen oxides. Other greenhouse gases are emitted by human activity in smaller quantities. The combustion of coal, oil and gas produces carbon dioxide and nitrogen oxide, among the main causes of emissions of these pollutants. This is closely linked to a number of sources including vehicle traffic [2].

Globally, governments of countries have taken a number of actions to decarbonize and thus reduce $\mathrm{CO}_{2}$ [3]. Among the sources are vehicles and therefore Europe has promoted the diffusion of sustainable and resilient forms of mobility that do not incentivize the use of the private vehicle and also the diffusion of motor and electric vehicles. This work focuses on one of the European countries that currently have the highest rates of pollution from vehicle traffic, namely, Poland. Since 2016, Poland has been trying to implement climate change and warming measures that are amplified compared to Europe [4]. 
Several measures have been proposed and included in local policies considering the achievement of small-, medium- and large-scale objectives in terms of both demand and transport supply. In general, the former is related to travel habits, modal choices and travel frequency, and the latter is related to infrastructure and services.

The development of electromobility implies new approaches and the need to create new solutions in the field of energy management and vehicle operation [5].

Within these standards, electrification of road transport is encouraged to ensure the eventual full decarbonization of the sector. There are a number of national measures that can help reduce demand and drive the shift to cleaner modes. Measures include shifting car passengers to trains, car-buses, walking and cycling; improving road freight logistics and shifting road freight to rail; and increasing car and bus ridership. These strategies are in line with the Paris Agreement on Climate Change and the 2030 Agenda for Sustainable Development.

This can facilitate the fundamental changes needed to achieve the objectives of the European Green Deal. The EU's goal is to reduce greenhouse gas emissions by at least 55\% by 2030 and achieve climate neutrality by 2050 [6,7]. The bottom-up approach allows for a series of actions to be implemented from the local context (micro scale) while respecting European standards and therefore this can contribute, together with actions on the meso and macro scale, to the achievement of the set objectives. Furthermore, it is important to highlight the studies that focus on the assessment of indicators related not only to the sustainability of cities but also to resilience, especially after the outbreak of the COVID19 pandemic event [8,9]. In general, the estimation of pollutant emissions from all road transport in a given region over a given period of time can be assessed both through the use of sensors and in a preventive manner through the use of emission models and the comparison of scenarios through simulation tools $[10,11]$.

The recent pandemic reduced these concentrations in some months of the 2020s due to the lockdown. At the planning level, the study of environmental impacts is covered in the sustainable urban mobility plans (SUMPs) [12] by defining the following objectives:

- $\quad$ ensure transport options for all citizens to access key destinations and services;

- improve safety conditions;

- $\quad$ reduce air and noise pollution, greenhouse gas emissions and energy consumption;

- improve the efficiency and cost-effectiveness of passenger and freight transport;

- contribute to improving the attractiveness of the territory and the quality of the urban environment and the city in general to the benefit of citizens, the economy and society as a whole;

- $\quad$ short-, medium- and long-term time frames are defined for impact mitigation. On an urban scale, it is essential to consider certain spaces such as intersections where vehicle flow is often concentrated during peak hours and where it is necessary to intervene to reduce the formation of vehicle congestion. In order to reduce emissions, it is therefore necessary to promote:

- the direct participation of the population in the strategic choices of local authorities in order to improve the quality of life;

- the dissemination of good practices from the urban scale and the assessment of possible mitigation actions in a preventive way;

- to reduce the use of own means of transport [13] and to encourage the purchase [14], sharing [15] or rental [16] of new forms of low-impact mobility.

Among the intersection schemes that provide the greatest benefits not only from a safety perspective [17,18] but also from a level of service [19] and emissions perspective [20] are roundabouts. In general, roundabouts have a better impact on the environment because they reduce pollution: the elimination of traffic lights reduces the time a car is stationary with its engine running at a given point.

There is also a reduction in traffic congestion. The benefits vary depending on the layout of the roundabout and the traffic flow and its composition. However, their diffusion in Europe is not homogeneous: while in Italy they are not yet regulated, they have already ap- 
peared for several years in other European countries such as Slovenia [21] and Poland [22] with benefits for safety and sustainability of transport [23]. The present work therefore focuses on the small-scale assessment of the environmental impacts (emissions) generated by different vehicle traffic scenarios in a multilane roundabout located in Rzeszow city in Poland.

The comparison with a new scheme was made by considering the turbo-roundabout, i.e., a roundabout with a high traffic density. In turbo roundabouts traffic flows run separately before entry into the roundabout and they occupy separate lanes all the way throughout the roundabout [24].

They may not be suitable for intersections with high demand volumes exceeding 4500 vehicles per hour, and whenever the traffic flow condition is oversaturated [25].

The physical separation of traffic lanes in turbo roundabouts allows for a reduction in points of conflict between vehicle flow and thus increases safety [26].

Several researches state that the performance of the turbo-roundabout is strongly influenced by the traffic load of the network, the directional distribution of traffic, both at the inlet and the outlet [27].

A preliminary study was carried out using a simulative-experimental approach adapted to one of the problems that afflict modern urban and metropolitan areas, namely, air pollution.

The objective pursued was to analyze the level of eco-compatibility of a multilane roundabout as a function of vehicle traffic and a comparison with a design scheme.

The results expressed in terms of concentrations of pollutants produced by vehicles were obtained through indirect estimation, i.e., based on a simulation centered on the measurement of parameters that influence the production of pollutant emissions such as speed, traffic flow, percentage of heavy vehicles and road infrastructure geometry. These parameters are the input data for forecasting models of emissions and fuel consumption in the form of regression formulas or software.

The extremes of the vehicle flow range were defined by considering the flow recorded in the recent pandemic period as the minimum and the peak flow characterizing the analyzed roundabout as the maximum. This work therefore focuses on an assessment of pollutant emissions from pandemic and pre-pandemic flows in two geometric schemes (a current scenario and a projected scenario) in order to investigate the extent to which road geometry can promote pollution reduction under certain conditions.

\section{Methodology}

The research focused on assessing the emissions produced by vehicle traffic passing through one of Poland's multi-lane roundabouts.

The aim of the research was to compare the emissions of $\mathrm{CO}_{2}$, NOx and PM10, which arise during peak hours for the standard working day before the pandemic and for a day selected from during the COVID-19 lockdown for Poland. Therefore, the research focused on a first phase of vehicle flow data acquisition and geometric data of a multilane roundabout intersection at Rzeszow.

A design scheme, i.e., a turbo-roundabout, was then hypothesized in order to understand what benefits it could bring in terms of pollutant emissions as well as vehicle traffic. A second step of the investigation assessed how the variation of traffic volume along the ring of the two roundabout schemes can bring about a greater or lesser production of pollutants the implementation of the geometric-functional and traffic parameters; processing was performed using microsimulation software, VISSIM [17,28,29]. Appropriate calibration of the VERSIT+ pollutant dispersion model allowed analyzing of two roundabout schemes (existing and projected) and finally to make some optimal considerations for the implementation of sustainable mobility strategies.

This comparison was useful for advance understand of the ranges within which it is better to replace the current roundabout scheme with the hypothetical one. The study focused on the following phases: 
- the collection of traffic data and vehicle composition,

- the choice of the geometric design scheme to be compared with the current condition,

- calibration of the micro simulation model,

- data processing,

- $\quad$ analysis of the results related to the concentrations of the main pollutants.

\subsection{Case Study Description}

Most air pollution in Poland is the result of the country's dependence on coal to power its homes and economy. The smog problem will affect most of Poland (Figure 1). It contributes to a large degradation of the natural environment and significantly affects the health of the inhabitants. In addition, the problem of air pollution is exacerbated by vehicles, which causes permissible standards for concentrations of harmful exhaust components to periodically be exceeded several times.

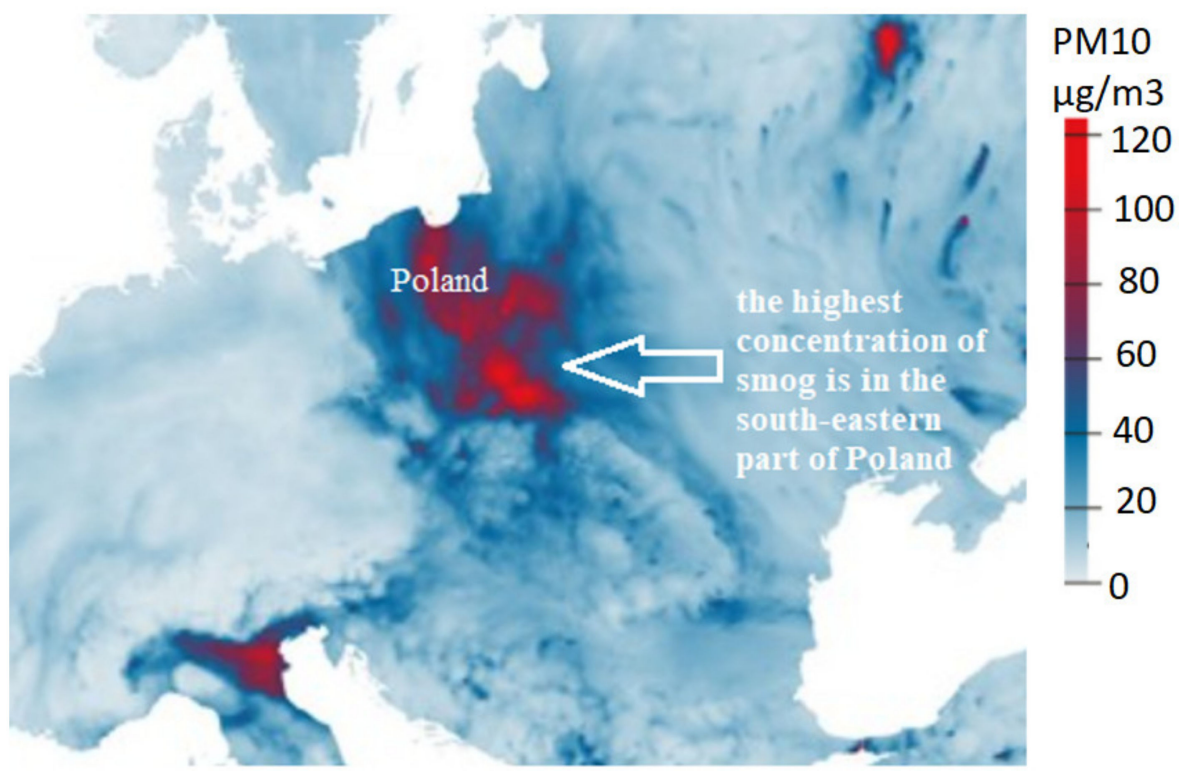

Figure 1. Level of PM concentration pollution in the air in Europe as at 18 January 2021. Based on [30].

In particular, the problem of smog occurs in the south-eastern part of Poland for the Sub-Carpathian part, whose capital is Rzeszow, a city that is a case study. Rzeszow is a city with approximately 200,000 inhabitants. The city is divided into 30 regions.

The city is an important transport hub, located about $90 \mathrm{~km}$ from the borders with Ukraine and Slovakia.

As a result of urbanization and the expansion of borders, Rzeszow suffers from unfavorable effects related to the constantly increasing number of vehicles. This state of affairs contributes to the growing problem of congestion and the increase in travel time [31]. The analyzed area is characterized by a multilane roundabout as described in Figure 2.

In the area of the roundabout, there are numerous large-format stores, a school and a hospital, the roads that make up the roundabout are also exit roads from the city, so as a result of overlapping the above-mentioned items, numerous congestions occur during rush hour. The current scheme was compared with a turbo roundabout. In general, it is possible to observe two groups of turbo roundabouts currently used in Poland. The first group consists of turbo roundabouts with geometry and traffic organization designed according to the model of Dutch turbo roundabouts with raised lane dividers. The other group is turbo roundabouts with traffic organization that corresponds entirely or partially on the traffic organization of conventional turbo roundabouts, but with no traffic islands, their function being carried out by a single continuous line of type P-2. Turbo roundabouts in 
the world are considered as solutions that are characterized by a high level of road safety and allow efficient flow at high traffic intensities [32].

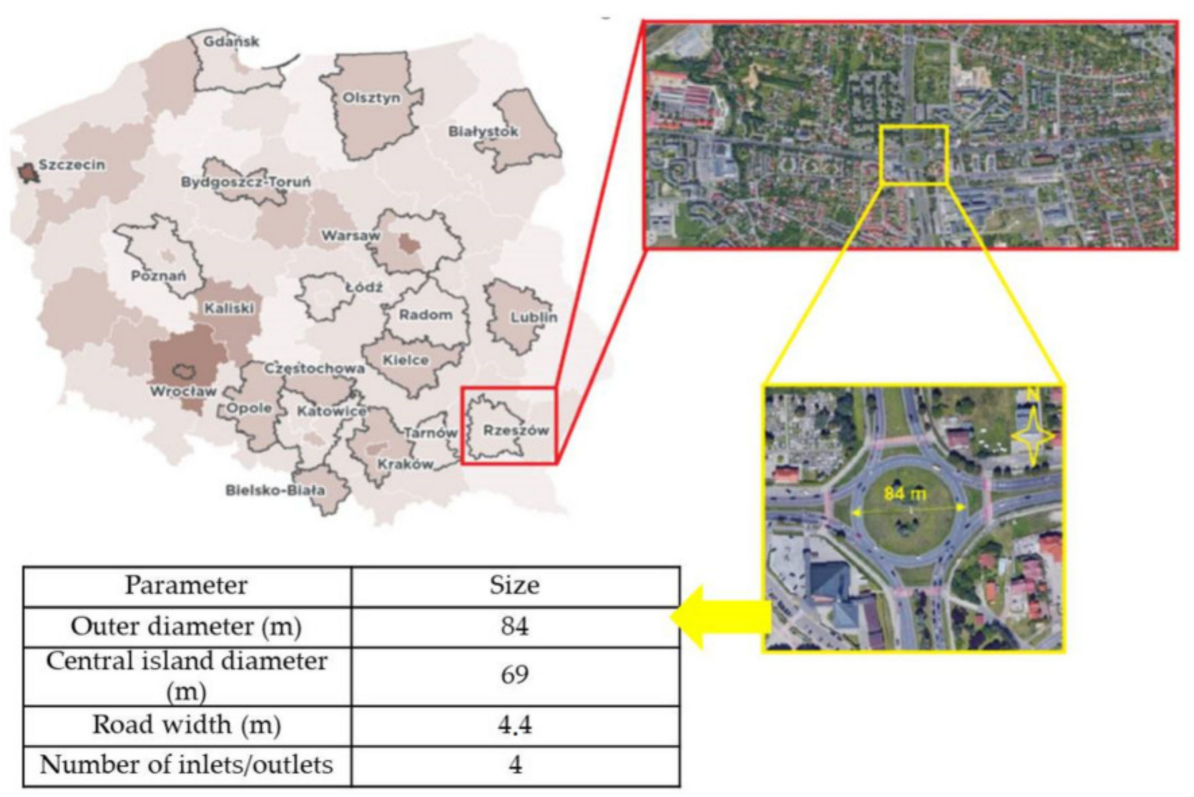

Figure 2. Glocalization of investigated area and relative road intersection in Rzeszow, Poland.

The roundabout under study was modeled using VISSIM software [33]. The roundabout area tested for simulation was limited to $300 \mathrm{~m}$ for access and exit roads from the roundabout.

\subsection{Roundabouts Models Constructions}

The aim of the research was to compare $\mathrm{CO}_{2}$, NOx and PM10 emissions, which arise during peak hours for standard working days before the pandemic and for a selected day from during the lockdown related to the COVID-19 for Poland. The comparison concerned the generation of emissions from vehicles for the current multilane roundabout (Figure 3) and the alternative version of the turbo roundabout (Figure 4), which was based on the current one.

The results were compared by micro-simulation analysis, i.e., by comparing different geometric schemes and considering the theory of car-following underlying VISSIM. In particular, it contains two models of psychophysical perception of car-following: Widedemann 74 and Wiedemann 99 [33]. The first model is most commonly used to model urban traffic. The estimation of emitted concentrations was referred to two vehicular flow conditions, namely, minimum flow and peak flow. The first condition occurred recently due to the pandemic effect by reducing the traffic flow by more than $50 \%$. Pollutant concentrations were estimated using VERSIT+ emission-calculation software. An important issue in the traffic simulation in VISSIM is also the question of the terrain height profile, which is a key parameter in calculating the emissions from the modeled models. Therefore, road models were developed on the basis of actual terrain height profiles for access and exit roads and the intersection area. 


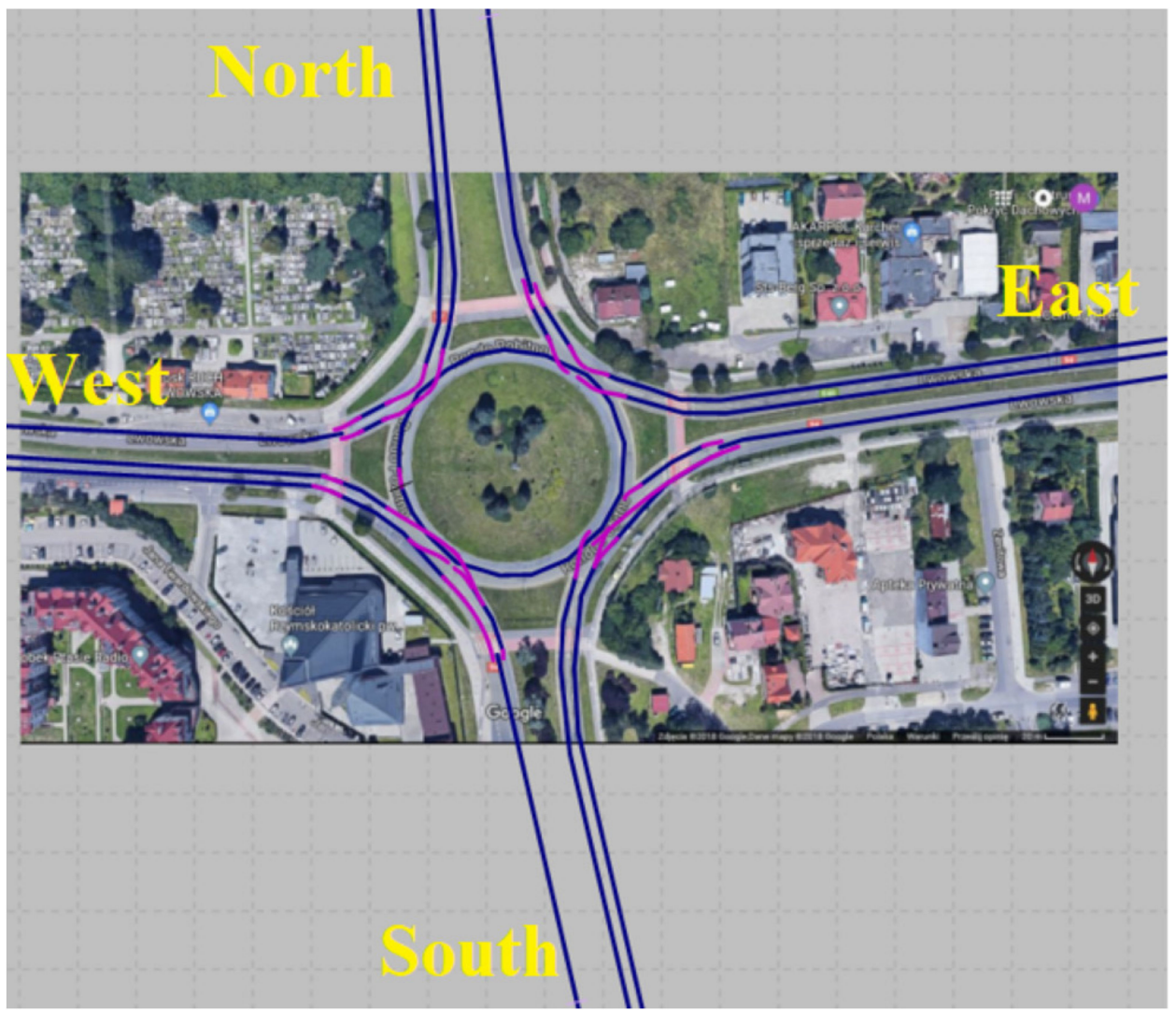

Figure 3. Researched modeled multilane roundabout.

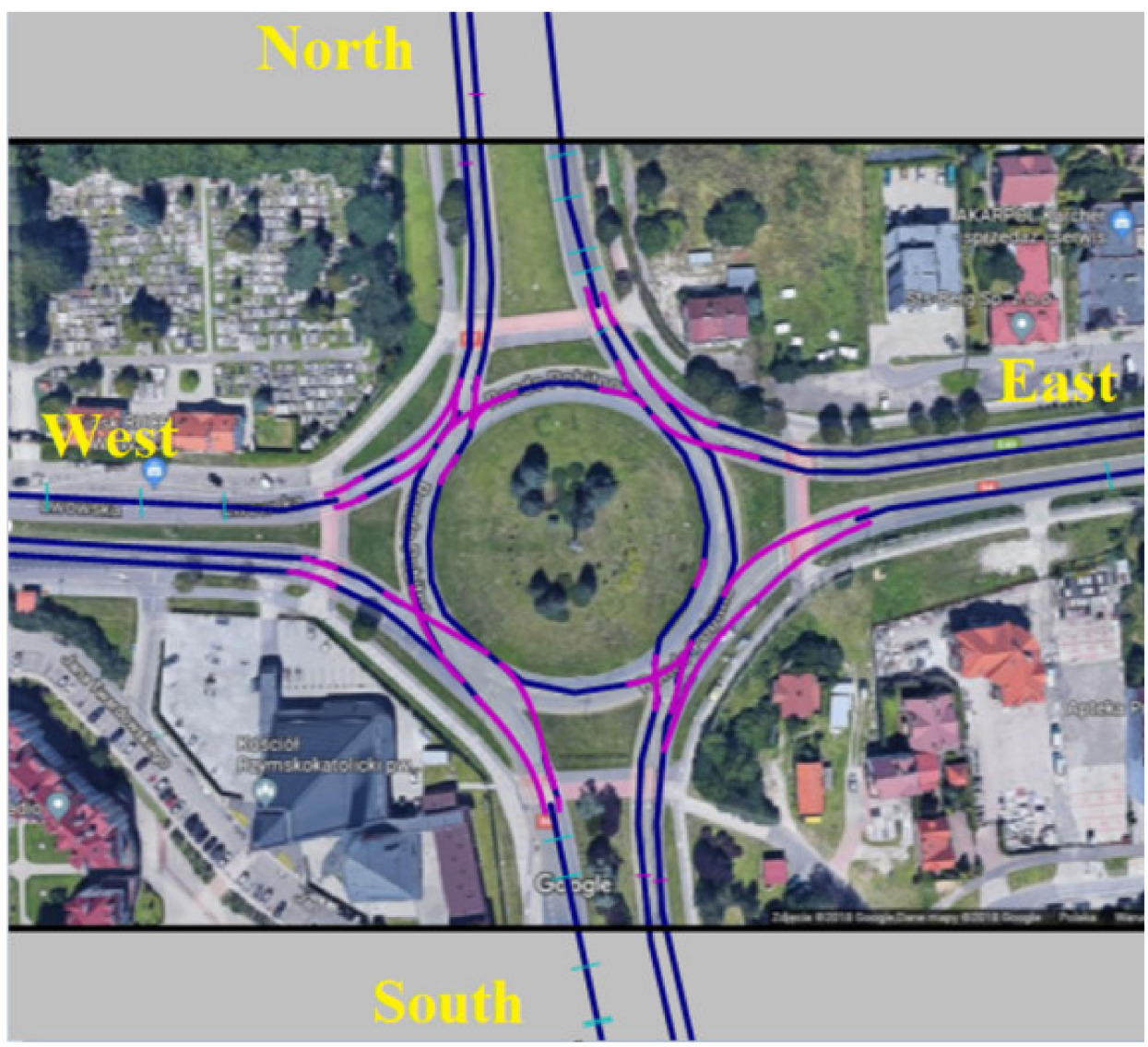

Figure 4. Alternative turbo roundabout scheme on actual area and software layout. 
The model structure of the researched multilane roundabout is shown in Figure 3. In order to create a route for vehicles entering the multilane roundabout, the access roads to the roundabout were modeled as single sections. This is because cars arriving at the roundabout must determine which lane they will occupy in advance, as this is the direction of the roundabout. The inlet and outlet roads to/from the roundabout are limited to a distance of $300 \mathrm{~m}$ from the center. To compare the currently operating multilane roundabout, in the context of the emission of exhaust pollutants generated by the traffic on the roundabout and in its vicinity, an alternative turbo version was modeled in its place. In order to create traffic separators characteristic of turbo roundabouts, all roads, except for exit roads from the roundabout, were modeled on the basis of single sections to level the intersection of vehicle streams. The model of the alternative turbo roundabout is shown in Figure 4 .

\subsection{Traffic Input Data Description}

The volume of road traffic is counted on the basis of data of car journeys from induction loops and cameras recording traffic located at the intersection inlets. Examples of data for the studied periods concerning the volume of vehicles for the day measured before the COVID-19 pandemic and for one of the days during full lockdown, when the epidemic prevailed, are presented in Figure 5.

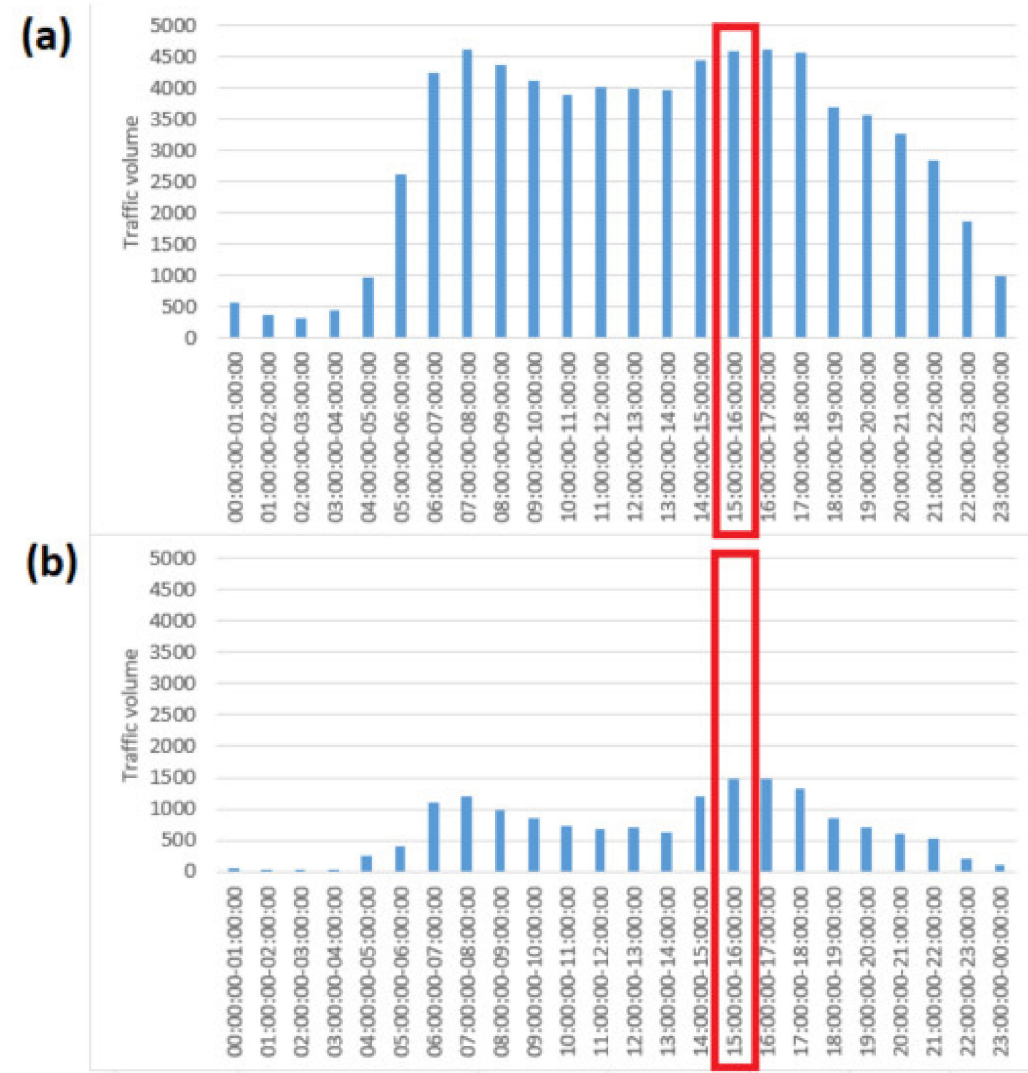

Figure 5. Traffic volumes for the analyzed period: (a) for working day 7 January 2020 (b) for lockdown COVID-19 day 24 March 2020 (red rectangles highlighted researched traffic volumes).

The tested simulation scenarios developed on the basis of real data from induction loops and cameras are presented in Table 1.

The calculation of emissions took into account data provided by the local database, the type of fuel used and the age of the vehicles [34]. 
Table 1. Traffic volumes for analyzed simulation scenarios.

\begin{tabular}{ccc}
\hline Traffic Conditions Scenario & Inlet & Traffic Volume \\
\hline & East & 1318 \\
Peak hours before COVID-19 lockdown & South & 1008 \\
(congestions occurs) & West & 863 \\
& North & 1342 \\
\hline & East & 284 \\
COVID-19 lockdown traffic during & South & 541 \\
peak hours (free flow conditions) & West & 312 \\
& North & 402 \\
\hline
\end{tabular}

Therefore, the following values for the composition of the circulating vehicle flow were considered in this study and were applied to VERSIT+:

- $56 \%$ petrol vehicles

- $31 \%$ diesel vehicles

- $13 \%$ LPG

On the basis of these data, the parameters for compliance with the "EURO" emission standards were set as follows:

- $5 \%$ EURO1,

- $9 \%$ EURO2,

- $17 \%$ EURO3,

- $29 \%$ EURO4,

- $19 \%$ EURO5,

- $22 \%$ EURO6.

The present work shows the presence of universal emission factors for different assumed traffic volumes for the selected roundabout entrance and the roundabout circulation loop, as well as emission data with respect to queue length at the roundabout entrance.

\subsection{VERSIT+ Emission Model Description}

There are several different emission models that can be used for the Vissim simulation purpose. Some of them are based on distance-based average fuel consumption, average speed or power demand for energy. However, for the purpose of microsimulation the best emission model is the one which used the speed profile from the simulation. This is especially necessary when analyzing a particular emission factor or concentration on the given road links is required. Especially beneficial in mentioned terms is VERSIT+ which enables drawing the concentration of emission paths along the analyzed road corridors, which can be used particularly to compare schemes in a preventive way to mitigate possible impacts and improve mobility planning in the analyzed area. For example, this detailed emission map's results show that if the flow increases, certain emission concentration increase, so road administration or road designers can divert traffic elsewhere or change the road construction or even propose speed limits to mitigate the emission effect.

The VERSIT + model was used to calculate the emissions. The VERSIT + speed profile emission model used in Enviver is a multi-factor regression model in which the variable is the driving cycle of a given vehicle. This requires the prior obtaining of speed profiles in VISSIM, on the basis of which it is possible to estimate the emission factors $(\mathrm{g} / \mathrm{km})$ for different vehicle classes [35,36]. VERSIT + includes a series of 246 classes of emission models, the algorithms of which are appropriately determined for each of the vehicle categories and the type of toxic exhaust components. Contrary to the emission factors obtained from the New European Driving Cycle (NEDC), the speed profiles used in this model are representative of real road conditions [37]. The emission factors $(E F j, k, l)$ are obtained from multiple linear regression to find empirical relationships between the emission rate, the velocity profile and the dynamic variables [38]. 
In accordance with [39] the emission of exhaust pollutants from road transport $(\mathrm{g} / \mathrm{h})$ for a specific exhaust component from one or more road sections is calculated as described below:

$$
T E j=\sum k, m\left(E F_{j, k, l} \cdot T V_{k, m} \cdot L_{m}\right)
$$

where, $E F_{j, k, l}$-emission factor $(\mathrm{g} / \mathrm{km}), j$-exhaust component, $k$-vehicle class, $l$-speed profile, $T V_{k, m}$-traffic volume (veh/h), $m$-road section and $L_{m}$-road length $(\mathrm{km})$. The speed profiles obtained from VISSIM are the input files for the VERSIT+ model after calibrating the model according to the desired speed and acceleration functions on the basis of empirical data. It is then necessary to define the fleet composition according to the previously mentioned statistical data including the percentage of particular emission class, the fuel used and age of vehicles. The calculation of the emission coefficient based on the multivariate regression model was presented. The general scheme of the performed emission calculation is presented in Figure 6.

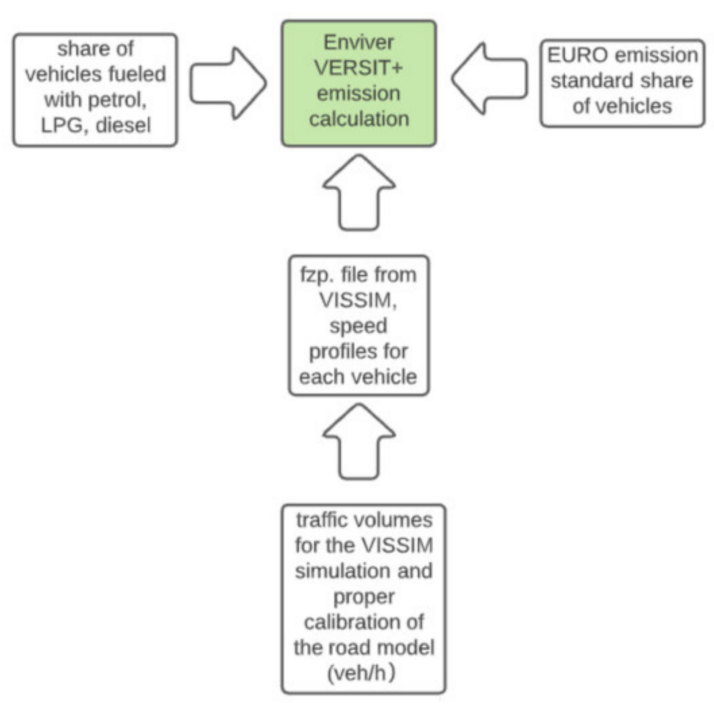

Figure 6. General step by step scheme of the VERSIT+ emission calculation.

\subsection{Simulation Models Calibration}

The process of traffic microsimulation is characterized by several steps. Initially it is necessary to calibrate the parameters that have a decisive influence on the movement of vehicles. In particular, it is necessary to calibrate the desired speed distribution parameter and acceleration. They have an impact on the subsequent vehicle emission results. The calibration was carried out considering real data from 14 vehicles and 9 different drivers. The input data for real world measurements for drivers were recorded by portable emissions measurement systems (PEMS) through built in global positioning systems (GPS) and also by separate GPS application for later comparison. The data concern the speed of the vehicles and their coordinates. Based on the coordinates the data were extracted for the roundabout region for further calibration. This detailed roundabout vehicle recorded data was particularly selected for $300 \mathrm{~m}$ from the inputs, the roundabout drive-through and for $300 \mathrm{~m}$ from the outlet of the roundabout. The recorded vehicle data was only limited to passenger cars, future research will focus on some other types of vehicles, such as trucks, buses, etc. The total number of road tests was 28 . The drivers were selected to obtain the largest possible scatter of data for different driving dynamics.

The desired speed was calibrated first, followed by the desired acceleration and deceleration. The purpose of this calibration was to achieve the greatest possible convergence of the velocity distribution and acceleration to real values. The parameters of the driving model behind the leader were then calibrated in order to achieve the closest possible values 
of the traffic volume at the individual inlets to the roundabout model, thus keeping the speed and acceleration distribution at the earlier, calibrated values.

In VISSIM, the desired speed is defined as the distribution and not as a specific unit value [40]. For each type of vehicle, the desired speed distribution is a key parameter that influences the road capacity and the driving speeds achieved. The standard value of the desired speed distribution is an equal distribution between the minimum and maximum speed. The desired speed was assumed to be the speed at which the vehicle moves when arriving and passing through the tested roundabout in free traffic conditions, i.e., at speeds higher than $30 \mathrm{~km} / \mathrm{h}$.

Figure 7 shows the desired speed distribution function from the VISSIM tool developed on the basis of road tests.

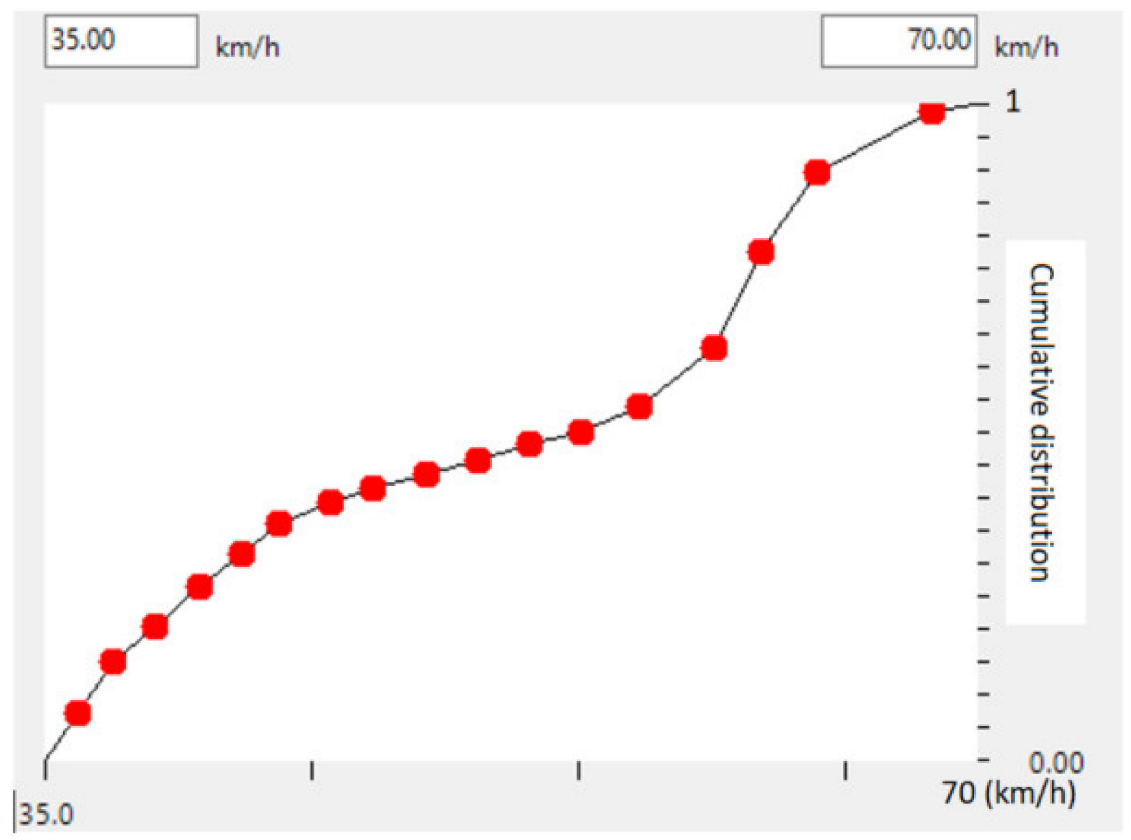

Figure 7. Desired speed distribution in VISSIM, based on road data.

Considering specific driving speeds, the software includes the functions of the desired acceleration and deceleration. The described functions are not constant values, because for each desired acceleration or delay in VISSIM, the minimum, average and maximum functions are determined. The values of these functions may be freely defined by the operator. Calibration of the desired acceleration can also be done in an intuitive way, as well as the calibration of the distribution of the desired speed by determining the average value of the acceleration in certain speed ranges. The maximum and minimum acceleration values can be defined as the 5th and 95th percentiles. However, drivers are not always able to drive at the desired acceleration, in particular when approaching a roundabout and driving around the roundabout envelope when there is another vehicle ahead.

The maximum desired acceleration is the 95th percentile, the minimum 95-p, and the average $95-\frac{1}{2}$ p. Figure 8 shows the summary distribution of identified accelerations. The observed accelerations in different speed classes were divided, while the parts exceeding the described percentiles were omitted in further considerations. The result of calibration of the desired speed in particular speed ranges is shown in Figure 9. 


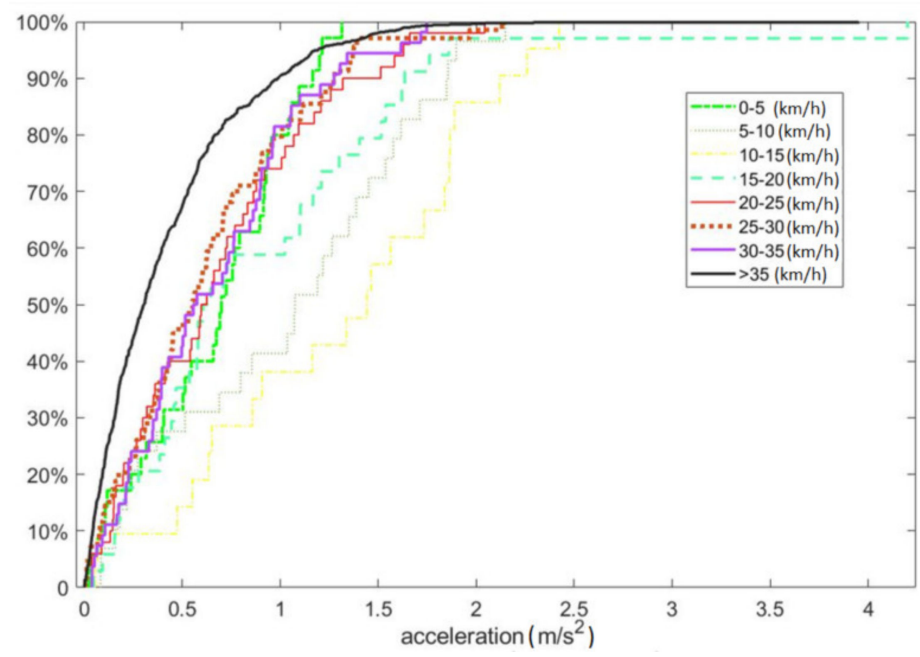

Figure 8. Summary of observed function of acceleration distribution for different speed classes.

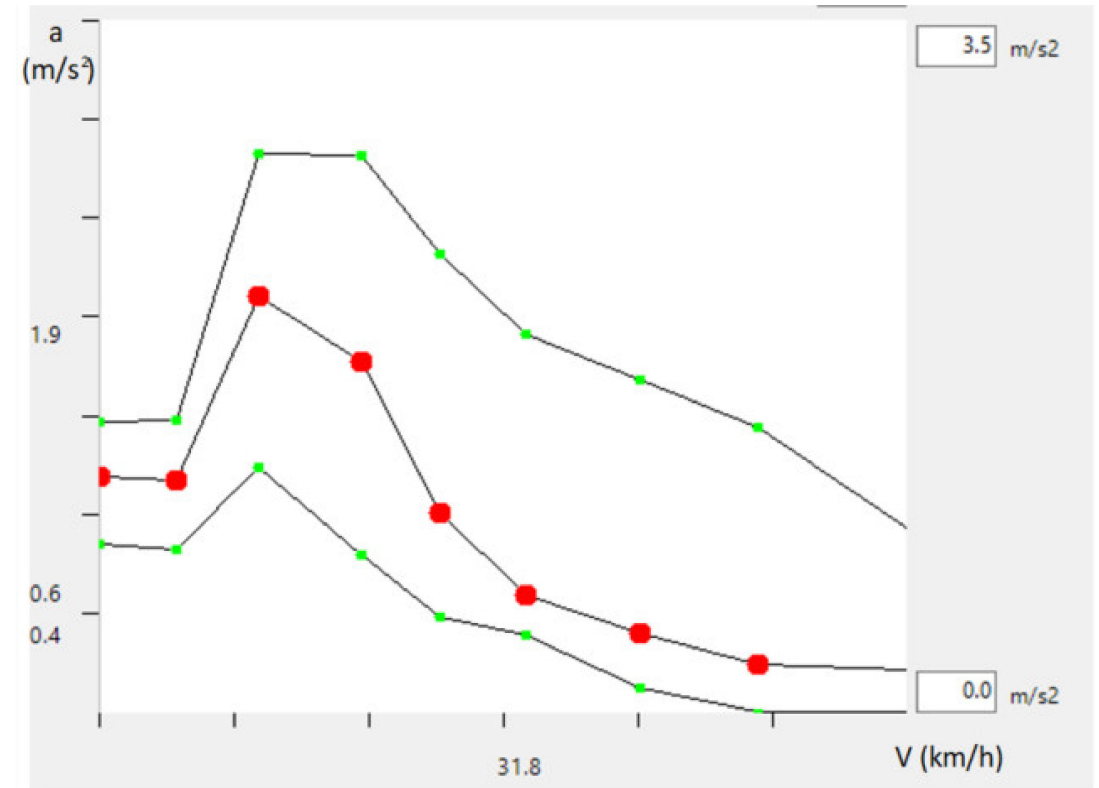

Figure 9. Calibrated desired acceleration distribution in VISSIM, based on road data.

In order to check the differences that arise when calculating the emissions from the model data before and after calibration, comparative tests were carried out. The model before and after calibration was run three times with different values of the randomness coefficient. The emission results from the performed tests are presented in Table 2. The differences in the results of emission of harmful components are noticeable. The highest values are for NOx, while the lowest for PM10.

Table 2. Emission of researched compounds from simulation before and after calibration process $(\mathrm{g} / \mathrm{km})$.

\begin{tabular}{cccc}
\hline Test/Compounds & $\mathbf{C O}_{\mathbf{2}}$ & $\mathbf{N O}_{\mathbf{x}}$ & $\mathbf{P M 1 0}$ \\
\hline Before calibration & 229.6 & 1.2221 & 0.172 \\
After calibration & 214.2 & 1.1034 & 0.168 \\
Difference & $7.19 \%$ & $10.7 \%$ & $2.38 \%$ \\
\hline
\end{tabular}


The reason for the higher emissions for the pre-calibration data is the more aggressive driving style of the drivers in the simulation (higher acceleration values for low driving speeds). If it is desirable to test different model solutions in the VISSIM software in terms of the emissions generated, it is necessary to calibrate the model first, because the presented differences have a large impact on the final result of the exhaust emissions.

\section{Results}

More than 30 simulations were carried out for the model calibration process, while 40 simulations were performed for the purpose of proper research.

The two roundabout geometric schemes were modelled using VISSIM software, while the vehicle traffic data were imported into the emission calculation model using the VERSIT+ tool. Calculations were made for peak hour traffic data for the day before the pandemic and during the pandemic.

These scenario simulations were performed for both compared geometries.

Figure 10 shows the distribution of speeds and accelerations for the examined scenarios for the pre- and during-pandemic flows.

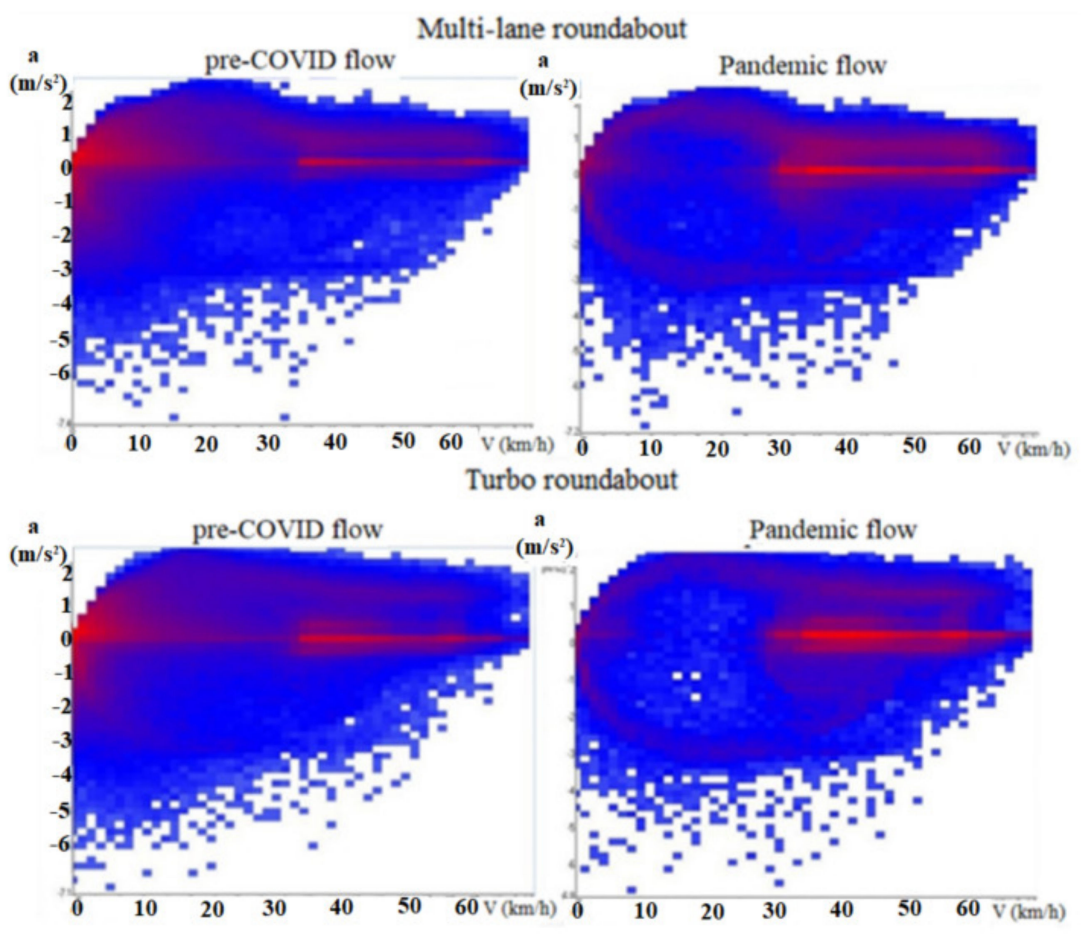

Figure 10. Speed vs. acceleration for analyzed roundabouts.

In particular, Figure 10 illustrates the obtained cumulative speed points as a function of acceleration for all researched vehicles from the simulation. On this basis, we can observe what the compaction looked like for the analyzed speed ranges in relation to the acceleration parameter (red-high density, blue-lower density). Based on Figure 9, it can be seen that for pre-COVID-19 flow there is higher density of low speed and acceleration points (red areas). This dependency applies to both multi-lane and turbo roundabouts. For lower traffic volumes for pandemic lockdown day, there is a clear advantage of a higher density of acceleration points from vehicles, which directly translated into smoother traffic and no major congestion.

Figures 11-13 show the emission maps of harmful exhaust components in and around roundabouts, while the average emissions are shown in Figure 13. 


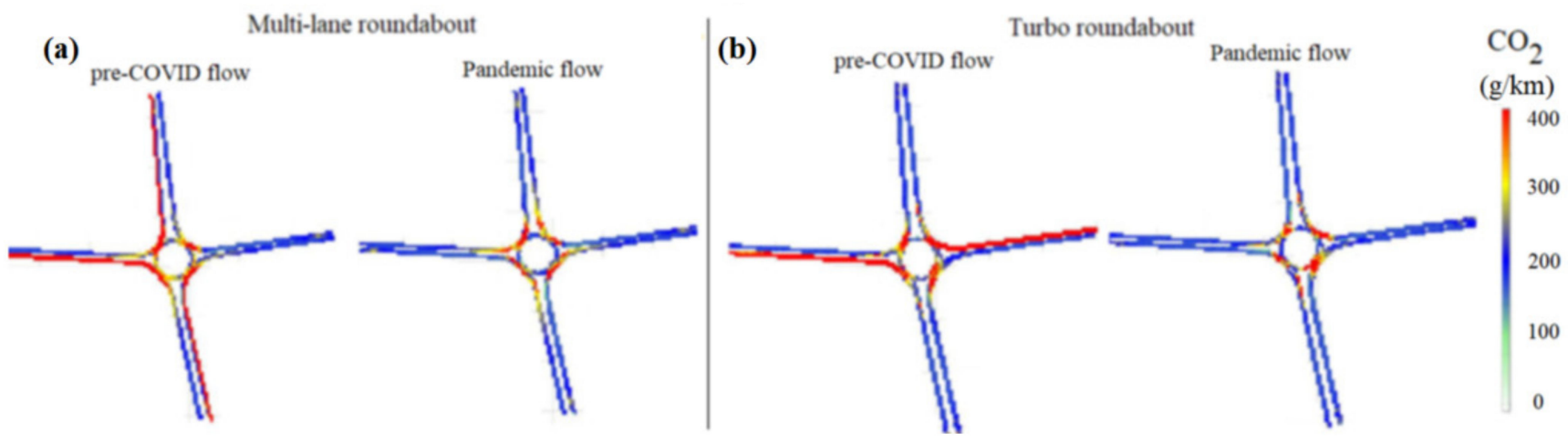

Figure 11. Map of emission of $\mathrm{CO}_{2}$ for the analyzed scenarios on multilane (a) and turbo (b) roundabout.

Based on Figure 11 it can be seen that the highest $\mathrm{CO}_{2}$ emission occurred for a multilane roundabout during the traffic rush hours before the pandemic and it exceeds the emission for a turbo roundabout at the same time by approximately $23 \%$; the maximum values for $\mathrm{CO}_{2}$ emissions occur in the vicinity of the access roads to the roundabout inlets as well as locally in the roundabout; the lowest $\mathrm{CO}_{2}$ emissions occur for the pandemic scenarios for both roundabouts.
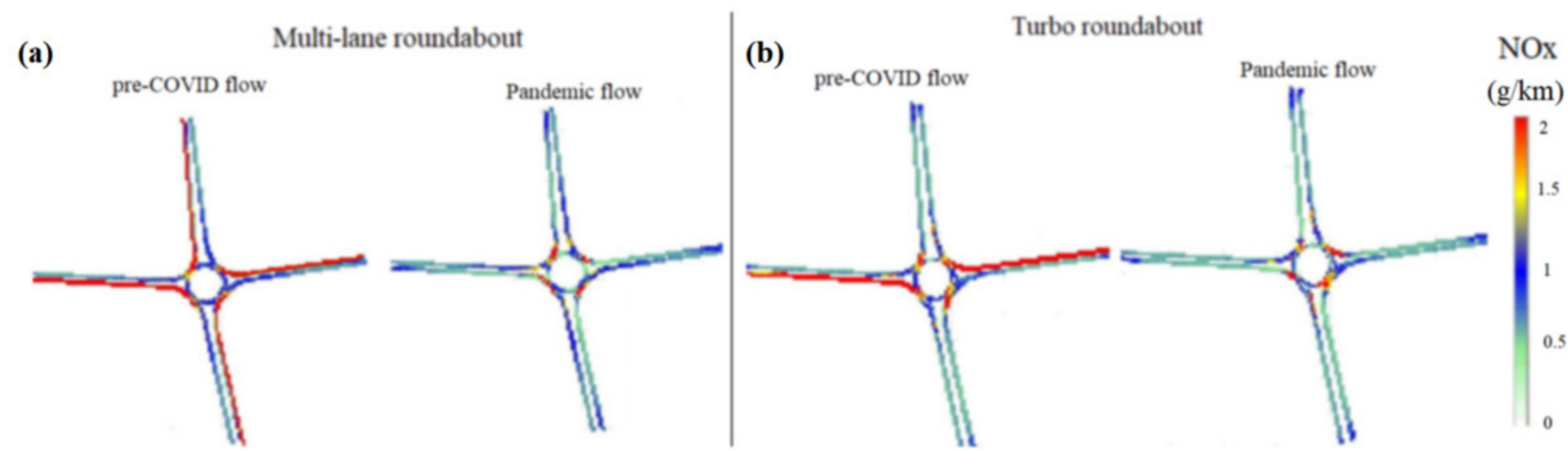

Figure 12. Map of emission of NOx for the analyzed scenarios on multilane (a) and turbo (b) roundabout.

Based on Figure 12 it can be seen that the highest NOx emissions occur for a multilane roundabout during pandemic free flow traffic conditions and concern entry at inlets; in the case of a turbo roundabout, it is smaller for the inlets allowing faster entry into and driving around the roundabout; the largest difference in NOx emissions occurs for the time before pandemic conditions and amounts to approximately $16 \%$ in favor of the turbo roundabout, while for pandemic day it is lower by approximately $9 \%$ for the same roundabout solution.

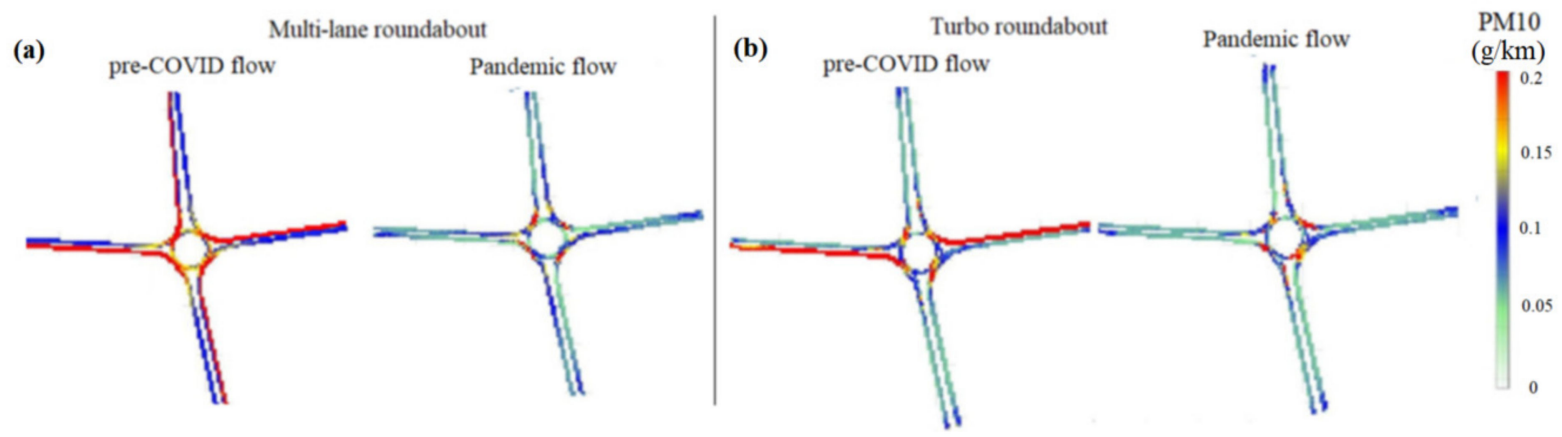

Figure 13. Map of emission of PM10 for the analyzed scenarios on multilane (a) and turbo (b) roundabout. 
Based on Figure 13 it can be seen that the highest PM10 emissions are for a multilane roundabout during peak traffic hours before the pandemic and the highest values are for inlets. Comparing the difference of PM10 emissions on a multilane roundabout and a turbo roundabout in the peak hours before the pandemic (approx. 23\%) and for pandemic conditions (approx. $2 \%$ ), in both cases it is in favor of the turbo roundabout.

The emission of the analyzed harmful exhaust components is directly related to the number of stops, driving speed and the acceleration of vehicles. At times when the traffic flow is high, the aforementioned parameters of vehicle traffic automatically deteriorate. The differences in exhaust pollutant emissions for the studied days of the pre-pandemic period and during the pandemic, for the currently operating multilane roundabout, are as follows (Figure 14): for $\mathrm{CO}_{2}-66 \%, \mathrm{NOx}-89 \%$ and $\mathrm{PM} 10-75 \%$, in favor of days during lockdown. Regarding the turbo roundabout, these differences are respectively: for $\mathrm{CO}_{2}-$ $29 \%$, NOx- $43 \%$ and PM10-39\%, also in favor of the day with widespread lockdown.

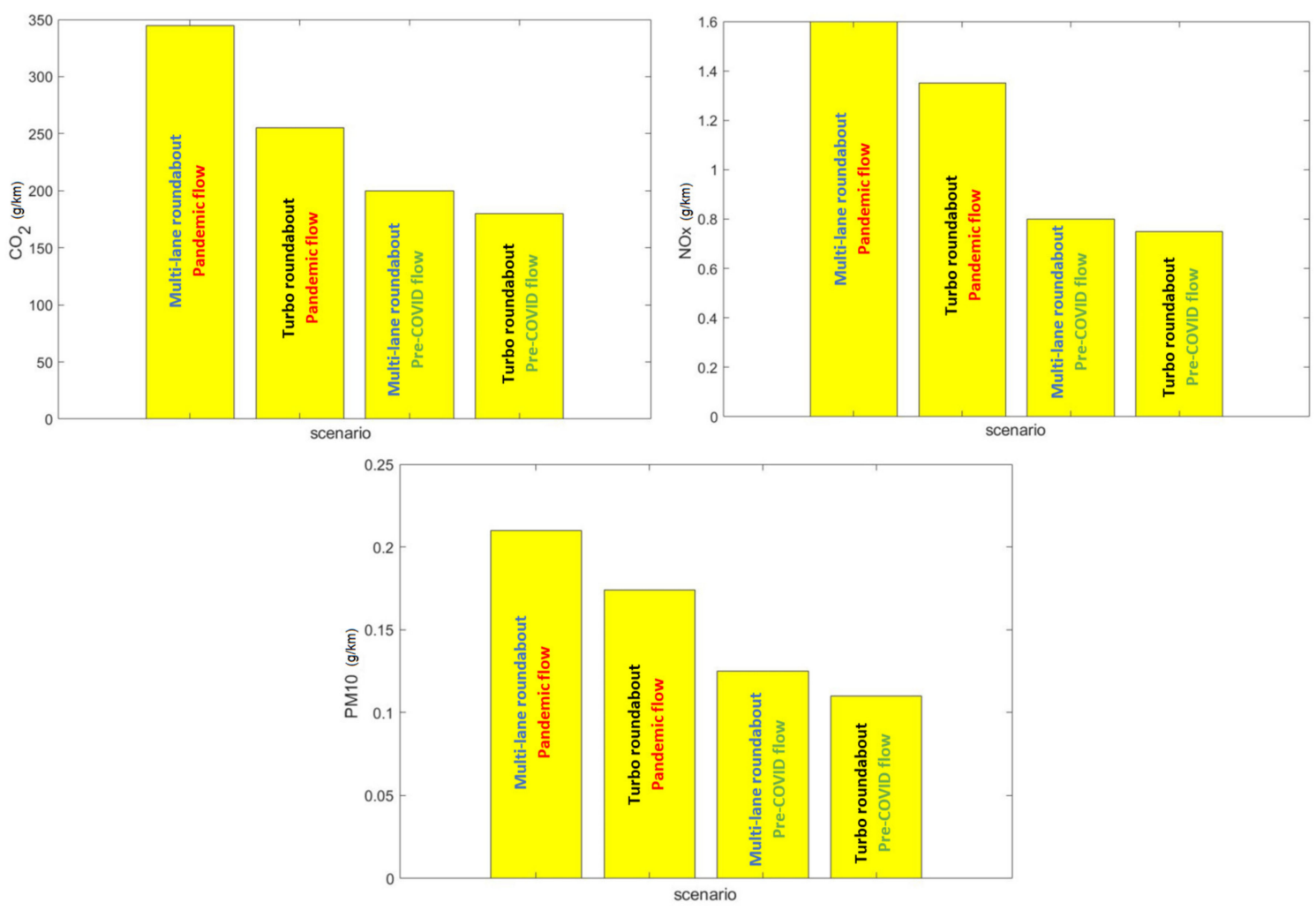

Figure 14. Emission of $\mathrm{CO}_{2}$, NOx and PM10 for analyzed scenarios.

Previous work [11,41] regarding comparison of two types of roundabouts for the same case study as presented in this work showed that besides changing the geometric shape of the two-lane roundabout into a turbo roundabout can in addition, result in a significant reduction in emissions due to the additional contribution of electric vehicles. This state of affairs determines not only that these vehicles are low-emission or zero-emission, but also the fact that they have other speed and acceleration problems related to a different specificity of engine operation, which additionally emphasizes the problem of model calibration in relation to selected parameters that are discussed in this work.

\section{Analyzing Different Traffic Volumes and Its Influence on Emissions Factors}

Due to the fact that the conducted analyses concern the investigated case study, it is necessary to perform further analyses related to other traffic volumes of vehicles, both for the circle of the roundabout and the inlets. Such a research could contribute to the development of more universal emission factors that characterize driving on a given 
roundabout. This could affect the updating of the documents related to the guidelines for the design of roundabouts with regard to ecological parameters. Previous studies concern the selected case studies for the assumed traffic volumes of vehicles, while in this part of the work, on the basis of numerous simulations for various traffic volumes, both for the inlets and for the roundabout envelope, the results can be generalized to general statements in relation to the different solutions applied for the structure of roundabouts. The works [41-43] showed that traffic at the roundabout is characterized mainly by three types of speed profile: without stops, with one stop before entering the roundabout envelopes and with many stops before entering the roundabout. In fact, in cities and during the day on busy roads crossing in the form of roundabouts, mainly the last two types of driving occur. The cases analyzed at work concern these types, with the predominance of driving with multiple stops. This state of affairs causes the engine to idle too often, which means that after another rapid acceleration, the vehicle generates higher emissions of harmful exhaust components.

To determine the amount of exhaust pollutant emissions depending on the vehicle traffic volume parameter, 36 simulations were carried out. The scenarios were developed according to the traffic flow data of the conflict stream (vehicles moving along the roundabout circle) and the traffic flow at the selected inlet. The simulations were carried out for two roundabout inlet options: a multilane roundabout inlet and a turbo roundabout inlet (traffic relations: north-south). For both roundabouts, the following scenarios for the traffic flow of the conflict flow for individual lanes were adopted (in the case of a multilane roundabout, the traffic volume was distributed symmetrically over the lanes): 600 - corresponds to low traffic intensity, 1400—corresponds to increased traffic intensity and 2000 - corresponds to high traffic intensity. The number of vehicles at the inlets was taken from 100/100 (right/left lane) to 600/600. The variation in $\mathrm{CO}_{2}, \mathrm{NOx}$ and PM10 emissions, depending on the described traffic flows, is shown in Figures 15-17.
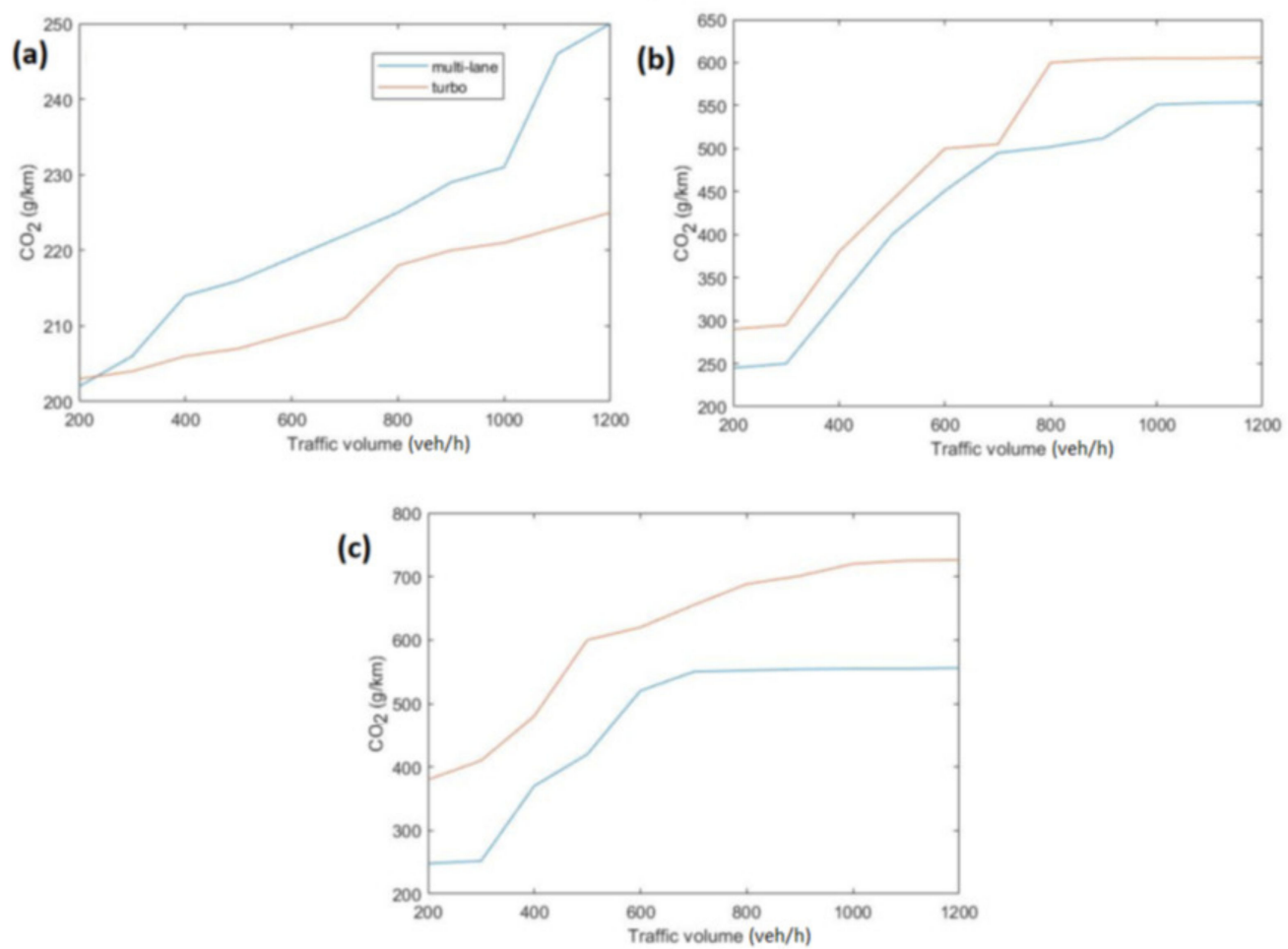

Figure 15. Emission of $\mathrm{CO}_{2}$ for the analyzed scenarios: (a) circular flow in the roundabout, 600 veh/h; (b) circular flow, $1400 \mathrm{veh} / \mathrm{h} ;(\mathbf{c})$ circular flow, $2000 \mathrm{veh} / \mathrm{h}$. 

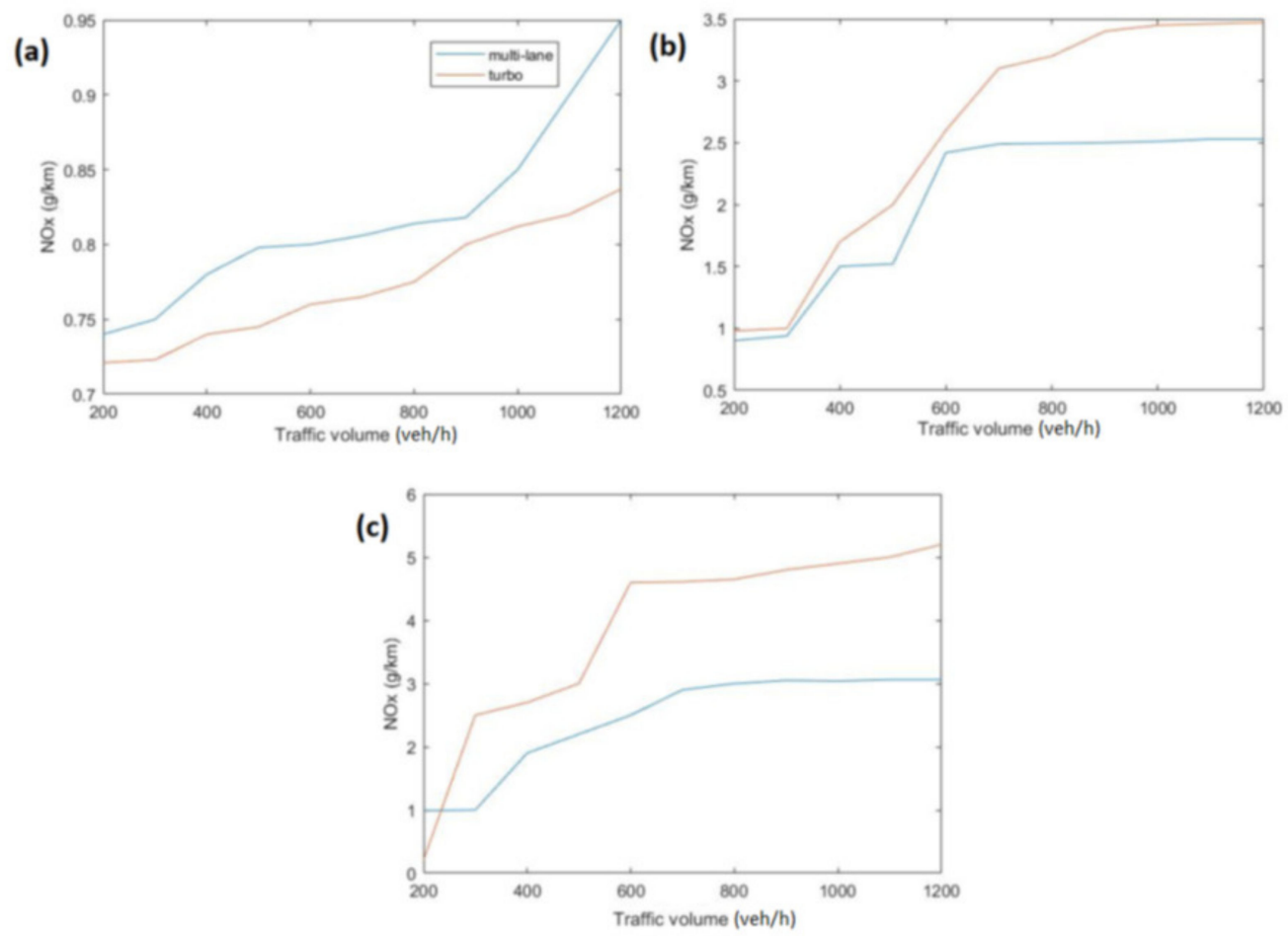

Figure 16. Emission of NOx for the analyzed scenarios: (a) circular flow in the roundabout, 600 veh/h; (b) circular flow, $1400 \mathrm{veh} / \mathrm{h}$; (c) circular flow, $2000 \mathrm{veh} / \mathrm{h}$.
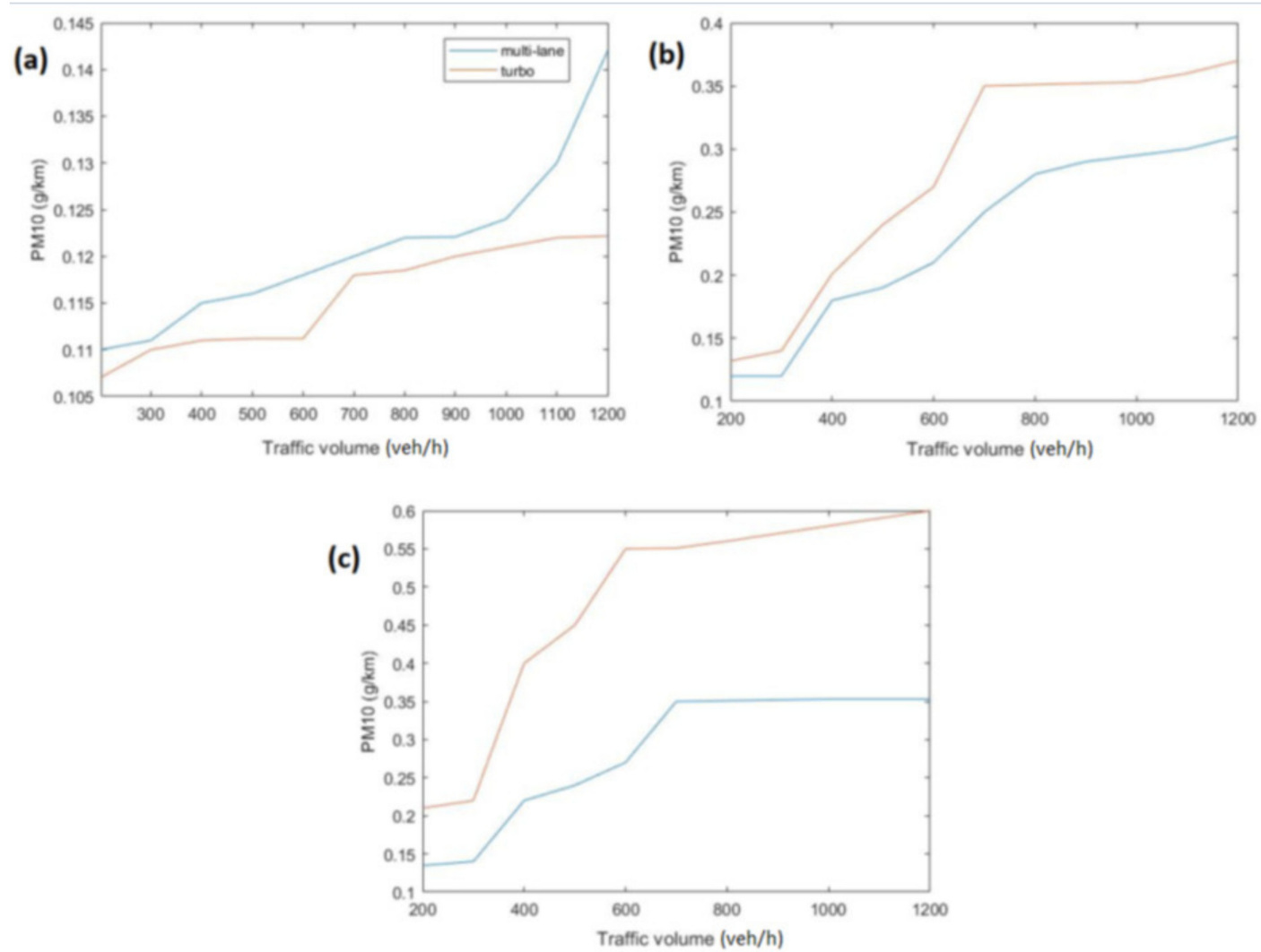

Figure 17. Emission of PM10 for the analyzed scenarios: (a) circular flow in the roundabout, 600 veh/h, (b) circular flow, $1400 \mathrm{veh} / \mathrm{h},(\mathrm{c})$ circular flow, $2000 \mathrm{veh} / \mathrm{h}$. 
Based on Figure 15 it can be seen that for the circular flow in the roundabout, 600 and 1400 vehicles $/ \mathrm{h}$, both for the multilane and turbo roundabout, $\mathrm{CO}_{2}$ emissions recorded a gradual increase in the value for the whole range of inlet volume, while for the volume of $2000 \mathrm{veh} / \mathrm{h}$ for the inlet vehicle volume of $700 \mathrm{veh} / \mathrm{h}$ (multilane roundabout) and $600 \mathrm{veh} / \mathrm{h}$ (turbo roundabout), the emission is set at a certain level and its changes are insignificant, which results from the super saturation of the model; comparing the $\mathrm{CO}_{2}$ emission values from the multilane to turbo roundabout model, it can be noticed that for the roundabout circular flow, $600 \mathrm{veh} / \mathrm{h}$, for the entire cross section of the inlet intensity, both the values and $\mathrm{CO}_{2}$ are lower for the turbo roundabout.

Based on Figure 16 it can be seen that for the circular flow in the roundabout of 600 vehicles/h, it can be noticed that from the value of $900 \mathrm{veh} / \mathrm{h}$ there is a visible increase in NOx emissions for a multilane roundabout. The same relationships can also be seen for the turbo roundabout in terms of circular flow in the roundabout of 1400 and $2000 \mathrm{veh} / \mathrm{h}$ for the traffic inlet volume of 300 and $500 \mathrm{veh} / \mathrm{h}$, respectively. In general, NOx emissions across the entire studied range also show an upward trend with increasing inlet vehicle loads; comparing the emissions from a multilane roundabout to a turbo roundabout, it can be noticed that for the traffic flow of the conflict stream of circular flow in the roundabout 600 , there is lower NOx emission for the turbo roundabout model, while for the remaining volumes, 1400 and $2000 \mathrm{veh} / \mathrm{h}$, the multilane roundabout is characterized by lower NOx emissions. This state of affairs is due to the fact that in the case of a multilane roundabout, traffic on both roundabouts is divided into two lanes, while on a turbo roundabout it accumulates on one lane.

Based on Figure 17 it can be seen that in terms of PM10 emissions for the scenario of circular flow in the roundabout of $600 \mathrm{veh} / \mathrm{h}$ for a multilane roundabout, a sharp increase in emissions from 1000 vehicles can be noticed, while for a turbo roundabout this can be observed from 600 vehicles. The values of PM10 emissions for the circular flow in the roundabout of 1400 to $500 \mathrm{veh} / \mathrm{h}$ for the traffic volume at the inlet are similar for both analyzed roundabout solutions. The case of circular flow in the roundabout of $2000 \mathrm{veh} / \mathrm{h}$ shows that for all the analyzed volumes at the roundabout inlet, the PM10 emission is higher for the turbo roundabout.

Another parameter of the vehicle traffic examined in relation to the emission of harmful exhaust components was the position in the queue of vehicles waiting to enter the roundabout.

The results presented in Figure 18 present the average emission values depending on the length of the queue of vehicles to enter the roundabout. Value 0 represents a situation where road conditions can be defined as free flow traffic.

The results of exhaust pollutant emissions presented in relation to the positions of vehicles in queues at the access to the roundabout refer to the average values obtained from all tested inlets from the simulation models. The emission of exhaust pollutants at the access roads to the roundabout depends on the number and length of vehicle stops. The presented results are a linear regression of all individual vehicle data from the beginning of the analyzed section of the inlet to the roundabout entrance. Based on them, it can be concluded that:

- $\quad$ along with the increase in the length of the queue of vehicles from 0 to $300 \mathrm{~m}, \mathrm{CO}_{2}$ emissions from the initial value increases by approximately $180 \%$ for a multilane roundabout, and by approximately $160 \%$ for the turbo roundabout,

- the increase in NOx and PM10 emissions for the queue length from 0 to $300 \mathrm{~m}$, both for the multilane and turbo roundabout, is similar and amounts to approximately $220 \%$ for NOx and approximately 300\% for PM10. 

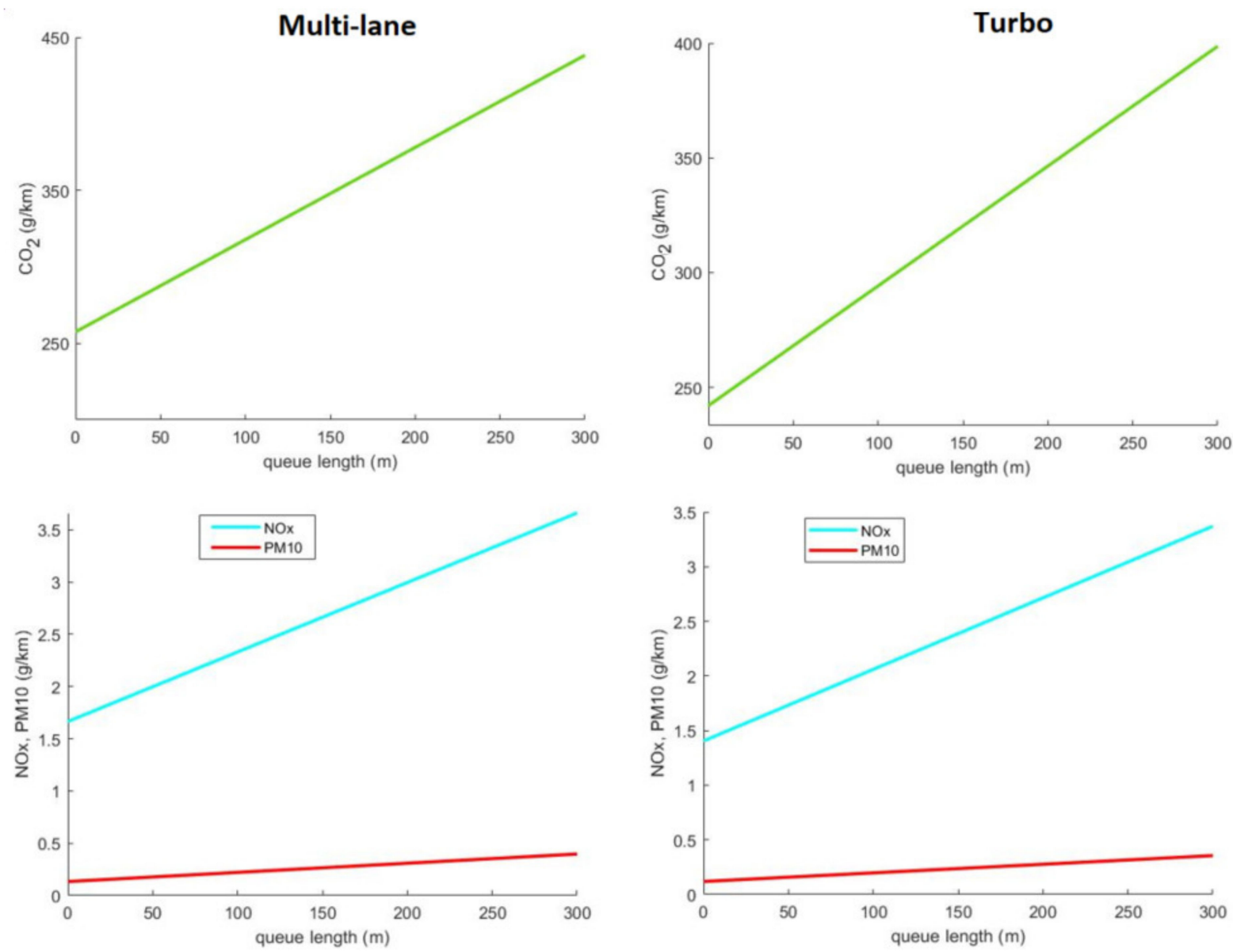

Figure 18. Emission of $\mathrm{CO}_{2}, \mathrm{NOx}$ and PM10 in relation to length of the vehicle queue.

\section{Conclusions}

The research provides some interesting and potentially useful results in outlining the influence of roundabout design on $\mathrm{CO}_{2}$ and air pollutant emissions from car traffic under different traffic flows. This methodology can be applied to other urban and nonurban contexts. This first step of research has shown how traffic conditions can influence the function of roundabout intersections as an eco-friendly intervention in the urban environment for the enhancement of sustainable mobility planning. The stop-and-go phenomena, especially at multilane roundabouts, result in significant emissions of harmful gases and significantly higher fuel consumption than would be the case under conditions of smooth traffic flow. Therefore, it is possible to state that roundabouts are intrinsically ecocompatible only when the values of the transport parameters testify to that "continuous" operation that is at the basis of the very concept of a roundabout; this corresponds to values of the capacity/capacity ratio lower than unity and to average delays of stops in the branches that can be traced back to service levels far from the limit situation. The methodological approach adopted, i.e., the simulative-experimental one, is well suited for a rational characterization of one of the problems that afflict modern urban and metropolitan areas, i.e., air pollution.

The main driving force behind greenhouse gas emissions from transport is fleet size, fleet composition, modal share of car traffic and kilometers travelled. Traffic flow may have some impact, as shown in the article, but the authors do not discuss how relevant it is to these other factors. The optimization of interventions at urban scale has to consider a preventive and comparative evaluation of several scenarios concerning both traffic composition and possible new geometric-functional scenarios. 
The comparative study is performed to understand which variations of pollutant concentrations could be present in the analyzed city and which could be potential risks for human health deriving from air pollution in the vicinity of the roundabout (e.g., pedestrians, motorists, residents). The results contribute to a small-scale view, i.e., on a limited area, and may only partially contribute to larger-scale emission levels in the city or country. Furthermore, the limitations for the simulation studies, particularly in the emission aspect, are some real-world parameters that are not analyzed in detail. Among others we can distinguish weight of the vehicle which is particularly related with the number of passengers and in the emission models it is not that clear to set up. However, despite the many disadvantages of the simulation, which is a generalization of what takes place in reality, it is possible to accurately reproduce the driving trajectory itself, for which the calibration methodology is presented in the paper. The simulated vehicle traffic input data in combination with accurate emission models are the only option for micro-scale emissions calculations, as it is impossible to equip every vehicle that crosses the researched road section in real life situations. As mentioned above, small-scale view emission analysis might be very relevant for human health risks from air pollution in the vicinity of the roundabout (e.g., pedestrians, motorists, residents), but for emission levels in the city or country, they are probably insignificant. Therefore, the illustrated methodology and comparison can be useful in the planning phase and the results can help urban planners to better balance traffic planning and air quality. These assessments will need to be correlated with more in-depth studies of the infrastructure construction phases in order to be able to analyses the emissions produced during the construction cycle and understand whether the benefits of construction are optimal in environmental terms.

Author Contributions: Conceptualization, T.C. and M.M.; methodology, M.M. and A.J.; software, M.M. and T.C.; validation, H.K., P.W. and A.J.; formal analysis, T.C.; investigation, M.M.; resources, P.W.; data curation, M.M.; writing-original draft preparation, T.C., M.M., P.W., A.J. and H.K.; writing—review and editing, T.C. and M.M.; visualization, M.M., T.C. and A.J.; supervision, H.K.; project administration, P.W. and M.M.; funding acquisition, P.W. All authors have read and agreed to the published version of the manuscript.

Funding: This work was supported by the Ministry of Infrastructure and Development as part of the Eastern Poland Development Operational Program in association with the European Regional Development Fund, which financed the research instruments.

Institutional Review Board Statement: Not applicable.

Informed Consent Statement: Not applicable.

Data Availability Statement: Data is contained within the article.

Conflicts of Interest: The authors declare no conflict of interest.

$\begin{array}{ll}\text { Abbreviations } \\ \text { LOS } & \text { Level of service } \\ \text { SUMP } & \text { Sustainable urban mobility plans } \\ \mathrm{CO}_{2} & \text { Carbon dioxide } \\ \mathrm{NOx} & \text { Nitrogen oxides } \\ \text { PM10 } & \text { Particulate Matter with a diameter of } 10 \mu \mathrm{m} \text { or less } \\ \text { LPG } & \text { Liquefied petroleum gas } \\ \text { NEDC } & \text { New European Driving Cycle } \\ \text { Veh/h } & \text { the number of vehicles per hour (saturation flow) }\end{array}$

\section{References}

1. Bebkiewicz, K.; Chłopek, Z.; Lasocki, J.; Szczepański, K.; Zimakowska-Laskowska, M. The Inventory of Pollutants Hazardous to the Health of Living Organisms, Emitted by Road Transport in Poland between 1990 and 2017. Sustainability 2020, $12,5387$. [CrossRef] 
2. Mensink, C.; Gong, W.; Hakami, A. (Eds.) Air Pollution Modeling and Its Application XXVI, 1st ed.; Springer International Publishing: Berlin/Heidelberg, Germany, 2019; pp. 1-490.

3. Panoutsou, C.; Germer, S.; Karka, P.; Papadokostantakis, S.; Kroyan, Y.; Wojcieszyk, M.; Maniatis, K.; Marchand, P.; Landalv, I. Advanced biofuels to decarbonise European transport by 2030: Markets, challenges, and policies that impact their successful market uptake. Energy Strategy Rev. 2021, 34, 100633. [CrossRef]

4. Żuk, P.; Szulecki, K. Unpacking the right-populist threat to climate action: Poland's pro-governmental media on energy transition and climate change. Energy Res. Soc. Sci. 2020, 66, 101485. [CrossRef]

5. Tucki, K.; Orynycz, O.; Świć, A.; Mitoraj-Wojtanek, M. The Development of Electromobility in Poland and EU States as a Tool for Management of CO2 Emissions. Energies 2019, 12, 2942. [CrossRef]

6. Luè, A.; Bresciani, C.; Colorni, A.; Lia, F.; Maras, V.; Radmilović, Z.; Anoyrkati, E. Future priorities for a climate-friendly transport: A European strategic research agenda toward 2030. Int. J. Sustain. Transp. 2016, 10, 236-246. [CrossRef]

7. Xu, L.; Yilmaz, H.Ü.; Wang, Z.; Poganietz, W.R.; Jochem, P. Greenhouse gas emissions of electric vehicles in Europe considering different charging strategies. Transp. Res. Part D Transp. Environ. 2020, 87, 102534. [CrossRef]

8. Moraci, F.; Errigo, M.F.; Fazia, C.; Campisi, T.; Castelli, F. Cities under pressure: Strategies and tools to face climate change and pandemic. Sustainability 2020, 12, 7743. [CrossRef]

9. Campisi, T.; Basbas, S.; Skoufas, A.; Akgün, N.; Ticali, D.; Tesoriere, G. The Impact of COVID-19 Pandemic on the Resilience of Sustainable Mobility in Sicily. Sustainability 2020, 12, 8829. [CrossRef]

10. Jaworski, A.; Mądziel, M.; Kuszewski, H.; Lejda, K.; Balawender, K.; Jaremcio, M.; Jakubowski, M.; Wojewoda, P.; Lew, K.; Ustrzycki, A. Analysis of Cold Start Emission from Light Duty Vehicles Fueled with Gasoline and LPG for Selected Ambient Temperatures; SAE Technical Paper 2020-01-2207; SAE International: Warrendale, PA, USA, 2020.

11. Mądziel, M.; Campisi, T.; Jaworski, A.; Tesoriere, G. The Development of Strategies to Reduce Exhaust Emissions from Passenger Cars in Rzeszow City-Poland A Preliminary Assessment of the Results Produced by the Increase of E-Fleet. Energies 2021, 14, 1046. [CrossRef]

12. Torrisi, V.; Garau, C.; Ignaccolo, M.; Inturri, G. "Sustainable Urban Mobility Plans": Key Concepts and a Critical Revision on SUMPs Guidelines. In International Conference on Computational Science and Its Applications; Springer: Cham, Germany, 2020; pp. 613-628.

13. Vanderschuren, M.; Baufeldt, J. Ride-sharing: A potential means to increase the quality and availability of motorised trips while discouraging private motor ownership in developing cities? Res. Transp. Econ. 2018, 69, 607-614. [CrossRef]

14. Kumar, R.R.; Alok, K. Adoption of electric vehicle: A literature review and prospects for sustainability. J. Clean. Prod. 2020, 253, 119911. [CrossRef]

15. Roscia, M.; Lazaroiu, G.C.; Mingrone, L.; Pignataro, G. Innovative approach of the sharing E-Mobility. In Proceedings of the 2016 International Symposium on Power Electronics, Electrical Drives, Automation and Motion (SPEEDAM), Capri, Italy, 22-24 June 2016; pp. 1120-1126.

16. Campisi, T.; Akgün, N.; Tesoriere, G. An Ordered Logit Model for Predicting the Willingness of Renting Micro Mobility in Urban Shared Streets: A Case Study in Palermo, Italy. In International Conference on Computational Science and Its Applications; Springer: Cham, Germany, 2020; pp. 796-808.

17. Jaworski, A.; Mądziel, M.; Lejda, K. Creating an emission model based on portable emission measurement system for the purpose of a roundabout. Environ. Sci. Pollut. Res. 2019, 26, 21641. [CrossRef] [PubMed]

18. Jaworski, A.; Lejda, K.; Mądziel, M. Emission of pollution from motor vehicles with respect to selected solutions of roundabout intersections. Combust. Engines 2017, 168, 140-144. [CrossRef]

19. Mohamed, A.I.; Ci, Y.; Tan, Y. A novel methodology for estimating the capacity and level of service for the new mega elliptical roundabout intersection. J. Adv. Transp. 2020, 2020, 8467152. [CrossRef]

20. Tollazzi, T.; Tesoriere, G.; Guerrieri, M.; Campisi, T. Environmental, functional and economic criteria for comparing “target roundabouts" with one-or two-level roundabout intersections. Transp. Res. Part D Transp. Environ. 2015, 34, 330-344. [CrossRef]

21. Gallelli, V.; Perri, G.; Vaiana, R. Operational and Safety Management at Intersections: Can the Turbo-Roundabout Be an Effective Alternative to Conventional Solutions? Sustainability 2021, 13, 5103. [CrossRef]

22. Kieć, M.; Ambros, J.; Bąk, R.; Gogolín, O. Evaluation of safety effect of turbo-roundabout lane dividers using floating car data and video observation. Accid. Anal. Prev. 2019, 125, 302-310. [CrossRef]

23. Petru, J.; Krivda, V. An Analysis of Turbo Roundabouts from the Perspective of Sustainability of Road Transportation. Sustainability 2021, 13, 2119. [CrossRef]

24. Tollazzi, T.; Rencelj, M.; Turnšek, S. Slovenian experiences with turbo-roundabouts. In The 3rd International Book on Roundabouts; TRB: Washington, DC, USA, 2011; Available online: https://e-zbornik.gf.sum.ba/images/radovi/e_zbornik_03_01.pdf (accessed on 20 July 2021).

25. Elhassy, Z.; Abou-Senna, H.; Shaaban, K.; Radwan, E. The implications of converting a high-volume multilane roundabout into a turbo roundabout. J. Adv. Transp. 2020, 2020, 5472806. [CrossRef]

26. Guerrieri, M.; Mauro, R.; Tollazzi, T. Turbo-roundabout: Case study of driver behavior and kinematic parameters of light and heavy vehicles. J. Transp. Eng. Part A Syst. 2019, 145, 05019002. [CrossRef]

27. Silva, A.B.; Mariano, P.; Silva, J.P. Performance assessment of turbo-roundabouts in corridors. Transp. Res. Procedia 2015, 10, 124-133. [CrossRef] 
28. Quaassdorff, C.; Borge, R.; Pérez, J.; Lumbreras, J.; de la Paz, D.; de Andrés, J.M. Microscale traffic simulation and emission estimation in a heavily trafficked roundabout in Madrid (Spain). Sci. Total Environ. 2016, 566-567, 416-427. [CrossRef]

29. Campisi, T.; Tesoriere, G.; Canale, A. Microsimulation approach for BRT system: The case study of urban turbo roundabout. In AIP Conference Proceedings 2017; AIP Publishing LLC: Melville, NY, USA, 2017; Volume 1906, p. 190005.

30. Information Regarding the PM Concentration in Europe in 2021. Available online: https://www.economist.com/graphicdetail/2021/01/30/polands-coal-fired-home-heating-creates-widespread-pollution?utm_cam-paign=editorial-social\&utm_ medium=social-organic\&utm_source=facebook\&fbclid=IwAR3xTxEJw8CyEREPIV8r34_puKZnL8WUpUeLq7aVMjrZzwsVT7 ekDtxgxu8 (accessed on 31 January 2021).

31. Smieszek, M.; Dobrzanska, M.; Dobrzanski, P. Rzeszow as a city taking steps towards developing sustainable public transport. Sustainability 2019, 11, 402. [CrossRef]

32. Macioszek, E. The road safety at turbo roundabouts in Poland. Arch. Transp. 2015, 33, 57-67. [CrossRef]

33. PTV. A PTV VISSIM 2020 User Manual; PTV Gr: Karlsruhe, Germany, 2020; p. 1278.

34. The Website of the Polish Local Data Bank. Available online: https:/ / bdl.stat.gov.pl (accessed on 21 November 2020).

35. Smit, R.; Smokers, R.; Rabe, E. A new modelling approach for road traffic emissions: VERSIT+. Trasp. Res. Part D 2008, 12, 412-422. [CrossRef]

36. Smit, R.; Smokers, R.; Shoen, E.; Hensema, A. A New Modelling Approach for Road Traffic Emissions: VERSIT+ LD-Background and Methodology; Report 06.ORPT.016.1/RS.; TNO Science and Industry: The Hague, The Netherlands, 2006.

37. Smit, R.; Ntziachristos, L.; Boulter, R. Validation of road vehicle and traffic emission models-A review and meta-analysis. Atmosheric Environ. 2010, 44, 2943-2953. [CrossRef]

38. Smit, R.; Casas, J.; Torday, A. Simulating fuel consumption and vehicle emissions in an Australian context. In Proceedings of the Australasian Transport Research Forum, Brisbane, QLD, Australia, 3-6 October 2013.

39. Smit, R.; McBroom, J. Use of microscopic simulation models to predict traffic emissions. Road Transp. Res. 2009, $18,49-54$.

40. Li, Z.; DeAmico, M.; Chitturi, M.; Bill, R.; Noyce, D. Calibration of VISSIM roundabout model: A critical gap and follow-up headway approach. In Proceedings of the TRB 92nd Annual Meeting, Washington, DC, USA, 13-17 January 2013.

41. Mądziel, M.; Jaworski, A.; Savostin-Kosiak, D.; Lejda, K. The Impact of Exhaust Emission from Combustion Engines on the Environment: Modelling of Vehicle Movement at Roundabouts. Int. J. Automot. Mech. Eng. 2020, 17, 8360-8371. [CrossRef]

42. Coelho, M.; Farias, T.L.; Rouphail, N. Effect of roundabout operations on pollutant emissions. Transp. Res. Part D Transp. Environ. 2006, 11, 333-343. [CrossRef]

43. Salamati, K.; Coelho, M.C.; Fernandes, P.J.; Rouphail, N.M.; Frey, H.C.; Bandeira, J. Emissions Estimation at Multilane Roundabouts. Transp. Res. Rec. J. Transp. Res. Board 2013, 12-21. [CrossRef] 